\title{
INDUCTION OF IN VITRO FLOWERING OF INDONESIAN WILD ORCHID, Phalaenopsis amabilis (L.) Blume
}

\author{
Endang Semiarti', Ixora S. Mercuriani ${ }^{2}$, Agus Slamet ${ }^{1}$, Bekti Sulistyaningsih ${ }^{1}$, I. A. P. \\ Bestari' ${ }^{1}$, Soenghoe. Jang ${ }^{3}$, Y. Machida ${ }^{4}$, C. Machida ${ }^{5}$ \\ ${ }^{1}$ Faculty of Biology, Gadjah Mada University, Indonesia, \\ ${ }^{2}$ Graduate School of Biotechnology, Gadjah Mada University, Indonesia, \\ ${ }^{3}$ Academia Sinica BCST in ABRC, Taiwan (R.O.C.), \\ ${ }^{4}$ Division of Biological Sciences, Graduate School of Science, Nagoya University, Japan, ${ }^{5}$ College of \\ Biotechnology and Bioscience, Chubu University, Japan, \\ e-mail: endsemi@ugm.ac.id
}

\begin{abstract}
Orchids are generally cultivated for their flower. To induce flower initiation in Phalaenopsis amabilis orchid, genetic and physiological approaches were developed. Genetic modification by insertion of $P$. amabilis Flowering Locus $T$ ( $P a F T)$ gene driven by Ubiquitin promoter into orchid genome using Agrobacterium tumefaciens, whereas physiological approach was conducted by the use of growth regulators: N6benzyladenine $(B A)(1,3,9) \mathrm{mg} \cdot \mathrm{L}^{-1}$ or gibberellic acid $\left(\mathrm{GA}_{3}\right)(5,10,15) \mathrm{mg} \cdot \mathrm{L}^{-1}$ alone or in combination in culture medium. Orchid seeds were sown on New Phalaenopsis (NP) medium for 8 weeks, then subcultured on NP liquid medium $+\mathrm{BA}+\mathrm{GA}_{3}$ with shaking for 9 weeks. Developping protocorms were spread on NP solid medium, then supplemented with NP liquid medium $+B A+G A_{3}(5: 2)$. Cultures were maintained at $25^{\circ} \mathrm{C}$ with a photoperiod of $8 \mathrm{hrs}$ light/16 hrs dark. For genetic transformation, 3 weeks old protocorms were immersed overnight in cultures of $A$. tumefaciens with T-DNA harboring Ubipro::PaFT and Hygromycin phosphotransferase $(H P T)$ gene as selectable marker. Phenotypic analysis was carried out from 5-20 plants, each of them was observed for leaf and root number and lengths, comparing with untreated plants. Shoots with normal phenotype were generated from all treatments. RT-PCR analysis from 3 plants each of 4 weeks-24 months old-WT plants, 6 months old phytohormone treated plants and also 12 and 24 months old transgenic plants showed that $P O H 1$ juvenile gene transcript can be detected at juvenile stage of WT and PaFT mRNA was expressed in late stage after 6 months old WT plants. In all phytohormone treated plants and transgenic orchid both $P O H 1$ anf $P a F T$ transcripts can be detected in 5,12 and 24-months old plants, but no flower initiation was occurred. It indicates that post transcriptional inhibition might be occurred, and it needs to be explored.
\end{abstract}

Keywords: in vitro, flower, PaFT, growth regulators, Orchids

\section{INTRODUCTION}

Indonesia is a hotspot of tropical biodiversity, including natural orchids. There are about 5,000 orchids out of 30,000 orchids in the world distribute throughout our tropical rain forests. Some natural orchid become very popular as important horticultural plants because of the beauty and longlasting flowers. People cultivate orchids to get the flowers, for cutting flowers and ornamental pot plant. beside its other benefits. The difficulties is usually too long waiting time to get the first flowers from growing orchid. It because of the long duration of juvenile/vegetative stage, that can vary widely from one to13 years among orchids and the average time is between two to three years (Hew and Yong, 1997). Plant develops throuh 3 stages: embryo, juvenile (vegetative, and reproductive, in which coordinated by some genes that involved in genetic regulation (Howell, 1998). In orchid biotechnology, flowers can be induced by physiological and Genetic engineering approach.

ISSN 2413-0877 @ 2015 The Authors.

Published by KnowledgeE Publishing Services This is an open access article under the CC BY-NC-ND license (http://creativecommons.org/licenses/by-nc-nd/4.0) 
The use of in vitro flowering is significant as it shortens the breeding period of transgenic orchid, new hybrids and cultivars. For the commercial growers, breeders will get the results of their crosses sooner and this will improve the efficiency of varietal development by shortening the generation interval. A potential application of this approach is that the orchid breeding cycle can be further reduced if seeds can be succesfully obtained in vitro. Some reports are available on induction of early flowering in orchids using both tissue culture procedure with phytohormones and genetic engineering of flowering genes. Flowering includes flower initiation and floral development. In orchids, several studies showed that BA-induced floral bud required nutritional conditions such as ratio of carbohydrate and nitrogen. For example in Doriella Tiny orchid, floral bud can be induced in plants that grown on Vacin and Went media with $10 \mathrm{~g} \mathrm{L-1}$ sucrose and $5 \mathrm{mg} \mathrm{L-1} \mathrm{BAP} \mathrm{(Hew} \mathrm{and} \mathrm{Yong} \mathrm{1997).} \mathrm{Cytokinins} \mathrm{promote}$ flowering while auxins are inhibit, and GAs affect flower development rather than flower initiation (Hew and Yong, 1997). This paper aims to provide flower induction in Indonesian wild orchid Phalaenopsis amabilis (L.) Blume and discuss the possible ways to induce flowering by genetic and physiological approaches to meet market demands.

\section{MATERIALS AND METHODS}

\section{Plant Materials}

The plant materials were 3-6 weeks old $P$. amabilis protocorms. Protocorms are produced by sowing seeds from mature fruits (4 months after self pollination) on New Phalaenopsis (NP) medium that have been modified by addition of $150 \mathrm{ml}^{\mathrm{L} \mathrm{L}^{-1}}$ coconut water and $100 \mathrm{mg.L}^{-1}$ tomato extract (Semiarti et al., 2010).

\section{Plasmid Vectors and Bacterial Strains}

Agrobacterium tumefaciens strain LBA4404 that contains Ubi-pro::PaFT carrying plasmid (pGAS102) and empty plasmid (pGA3426) is used as the source of gene and control experiment, respectively. These clones were obtained from Dr. Soenghoe Jang (Academia Sinica, Biotechnology Center in Southern Taiwan).

\section{Co-cultivation and Selection}

Agrobacterium-mediated transformation was conducted according to Semiarti et al. (2007) with several modifications. A colony of both Agrobacterium that carry pGA3426 and pGAS102 inoculated in $5 \mathrm{ml}$ of liquid LB medium containing $5{\mathrm{mg} . \mathrm{L}^{-1}}^{-1}$ Tetracycline and incubated at $28^{\circ} \mathrm{C}$ for 2 days. After that, $1 \mathrm{ml}$ of this culture was subcultured in $9 \mathrm{ml}$ of new medium containing $50 \mathrm{mg.L}^{-1}$ Acetosyringone and incubated overnight. $10 \mathrm{ml}$ of Agrobacterium culture $(O D 600=0.8-1)$ were centrifuged at $5000 \mathrm{rpm}$ for 10 minutes. Bacterial pellets then resuspensed with NP medium. Suspension of bacterial culture was then diluted with liquid NP medium at ratio 1:4 (v/v) and used for cocultivation.

Prior to cocultivation, orchid protocorms were subcultured for 4 days in solidified NP medium containing $1 \mathrm{mg} \cdot \mathrm{L}^{-1}$ 2,4-D and $50 \mathrm{mg} \cdot \mathrm{L}^{-1}$ acetosyringone. In cocultivation, precultured protocorms were collected and immersed in diluted Agrobacterium suspension that is supplemented with 2 drops of Tween 20 and 50 mg. $\mathrm{L}^{-1}$ acetosyringone in a new sterile petridish for $30 \mathrm{~min}$. These protocorms were then transferred onto sterile filter paper to dry and cultured onto solidified NP medium containing $1 \mathrm{mg} . \mathrm{L}^{-1}$ 2,4-D and $50 \mathrm{mg} \cdot \mathrm{L}^{-1}$ acetosyringone. Elimi- 
nation of Agrobacterium was done by washing protocorms with sterile destilated water for 3 times and continues with washing medium (no sugar added liquid NP medium containing 25 mg. $\mathrm{L}^{-1}$ Meropenem). The last washing was done 2 days (the medium was changed every day) with agitation (100 rpm). Protocorms were then transferred onto sterile filter paper to dry and cultured onto solidified NP medium containing $5 \mathrm{mM}$ 2-IP, $0.15 \mathrm{mM} \mathrm{NAA}$, and 100 mg. L-1 carbenicillin for a week to inhibit Agrobacterium overgrowth. Growing protocorms were rinsed thoroughly with liquid NP medium containing $25 \mathrm{mg} \cdot \mathrm{L}^{-1}$ Meropenem, then transferred onto medium containing $5 \mathrm{mM} 2-\mathrm{IP}, 0.15 \mathrm{mM}$ NAA, $100 \mathrm{mg} \cdot \mathrm{L}^{-1}$ carbenicillin and 10 mg. $\mathrm{L}^{-1}$ Hygromycin as selection agent for 6 weeks. Subculturing on the same selection medium was done every 2 weeks. After selection, protocorms were regenerated on solidified NP medium containing $5 \mathrm{mM} 2-\mathrm{IP}, 0.15 \mathrm{mM}$ NAA.

\section{Analysis of the transgene in P. amabilis genome}

Analysis of gene insertion(s) in P. amabilis genome was performed by PCR. Genomic DNA was isolated from leaf of 6 mas (month after sowing) WT and transgenic plant (vector only (T1) and PaFT inserted transgene (T2). Amplification of Ubi-pro::PaFTDNA fragment from T2 performed using Ubiquitin (forward: 5'-TTGTCGATGCTCACCCTG-3 ') and TNos (reverse: 5'-GATCTAGTAACATAGAT GACACCGCG-3') primers, while transgene of T1 was amplified using HPT F 5'-TGCGCCCAAGCTGCATCAT-3'and HPT R 5'TGAACTCACCGCGACGTCTGT-3' primers. The DNA amplification was carried out by PCR using the following conditions: 5 min at $94^{\circ} \mathrm{C}$ for the first denaturation of DNA; 35 cycles of 1 min at $94^{\circ} \mathrm{C}$ for denaturation, $30 \mathrm{sec}$ at $54^{\circ} \mathrm{C}(\mathrm{PaFT})$ or $69^{\circ} \mathrm{C}(\mathrm{HPT})$ for annealing, and 1.5 min at $72^{\circ} \mathrm{C}$ for elongation; and $5 \mathrm{~min}$ at $72^{\circ} \mathrm{C}$ for post PCR. Amplified DNA was then checked on $1 \%$ agarose gel electrophoresis, stained with green fluorescence staining (Good View), and visualized with UV-transilluminator.

\section{RT-PCR analysis}

RT-PCR was carried out to analyze PaFT and POH1 gene expression in T1, T2, WT, and WT that were flowering induced by phytohormones, three plants each. Total RNA was extracted from leaf of 6 to 24 mas plant by using RNeasy Mini Kit (QIAGEN). Total RNA (1 $\mu \mathrm{g}$ ) was used to synthesize First-Strand cDNA using iScriptTM cDNA Synthesis Kit (BIORAD) according to the manufacturer's instructions. The CDNA $(1 \mu \mathrm{g})$ was used for amplification of $\mathrm{PaFT}$ or POH1. The cDNA amplification was carried out by PCR using the following conditions: $5 \mathrm{~min}$ at $94^{\circ} \mathrm{C}$ for the first denaturation of DNA; 35 cycles of $1 \mathrm{~min}$ at $94^{\circ} \mathrm{C}$ for denaturation, $30 \mathrm{sec}$ at $54^{\circ} \mathrm{C}(\mathrm{PaFT})$ or $69^{\circ} \mathrm{C}(\mathrm{HPT})$ for annealing, and $1.5 \mathrm{~min}$ at $72^{\circ} \mathrm{C}$ for elongation; and 5 min at $72^{\circ} \mathrm{C}$ for Post PCR. Primer pairs were as follow: PaFT F1 (5'GAKATGAATAGAGAGASRGAC-3') and PaFT R1 (5' TCAATCYTGCATYCTTCTTCC-3') for PaFT gene expression, POH1 F1 (3'-GAAGAGCTCACGAGGCCAGT-5') and POH1 R1 (3-CAAATAGCACCCAACCTTTC-5') for POH1 gene expression. Amplified DNA was then checked on $1 \%$ gel electrophoresis, stained with green fluorescence staining (Good View), and visualized with UV-transilluminator.

\section{Flowering induction by Phytormones}

Eight weeks after sowing (was) protocorm was subcultured on a medium of liquid NP with $\mathrm{BA}(0,1,3$, and $9 \mathrm{ppm})$ and combination of $\mathrm{BA}(0,1,3$ and $9 \mathrm{ppm})$ and $\mathrm{GA} 3(0,5,10$ 
and $15 \mathrm{ppm}$ ), and then was incubated on a shaker with a speed of $120 \mathrm{rpm}$ and temperature of $26^{\circ} \mathrm{C} \pm 2{ }^{\circ} \mathrm{C}$. Ten plants from each treatments were subcultured in new medium every 3 weeks for 9 weeks. Culture then was moved on the flowering medium consists of 2 layers (solid:liquid=5: 2). The lower layer was solid medium and the top layer was a liquid medium with a combination of $B A$ and GA3. Then culture was incubated at $26 \pm 2{ }^{\circ} \mathrm{C}$, with lighting conditions 8 hours of light and 16 hours of darkness.

\section{Analysis of phenotypes}

Analysis of phenotypes is carried out by observing the plant morphology (leaf number, root number, leaf length, and root length) from 5 plants each and the initiation time of inflorescence stalk. Observation and documentation were done every week since the induction of phytohormones until the formation of flowers.

\section{RESULTS AND DISCUSSION}

\section{Phenotypic analysis of P. amabilis development after induction of flowering}

Induction of in vitro flowering in $P$. amabilis by application of a combination of BA and GA3 in various concentration resulting in the change of plant development, especially the number and growth rate of leaf and root initiation and elongation (Table1 and Fig.1).

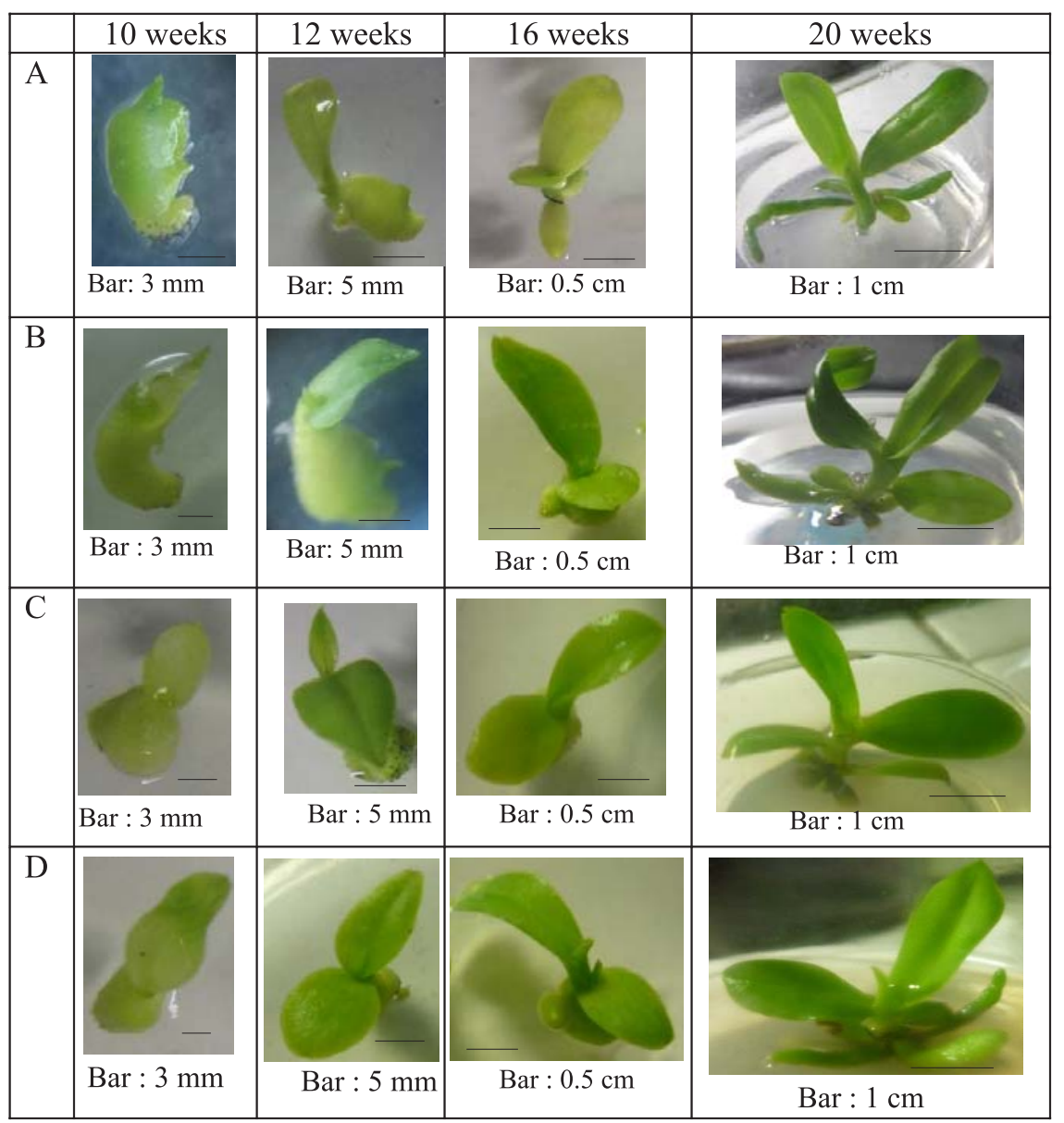

Figure 1. Development of in vitro culture of $P$. amabilis on liquid and solid medium with addition of phytohormone BA+GA3. A, control (untreated plants); B. Supplemented with 1 ppm BA +5 ppm GA3; C. supplemented with 3 ppm BA + 10 ppm GA3; D. supplemented with 9 ppm BA + 15 ppm GA3. 
Table 1. Phenotypic analysis of $P$. amabilis development after induction of flowering by phytohormones and PaFT gene transfer.

\begin{tabular}{lcccc}
\hline \multirow{2}{*}{ Treatment } & $\begin{array}{c}\text { Number of plants } \\
\text { examined }\end{array}$ & \multicolumn{3}{c}{ Leaf Length $(\mathrm{cm})$} \\
\cline { 3 - 5 } & & 12 weeks & 16 weeks & 20 weeks \\
\hline WT & 16 & $0.10 \pm 0.04 \mathrm{a}$ & $0.30 \pm 0.07 \mathrm{a}$ & $0.73 \pm 0.10 \mathrm{a}$ \\
BA 1 ppm GA3 5 ppm & 19 & $0.23 \pm 0.09 \mathrm{~b}$ & $0.61 \pm 0.10 \mathrm{~b}$ & $0.89 \pm 0.06 \mathrm{~b}$ \\
BA 3 ppm GA3 10 ppm & 19 & $0.45 \pm 0.04 \mathrm{c}$ & $0.75 \pm 0.12 \mathrm{c}$ & $1.06 \pm 0.11 \mathrm{c}$ \\
BA 9 ppm GA3 15 ppm & 20 & $0.64 \pm 0.07 \mathrm{~d}$ & $0.83 \pm 0.19 \mathrm{~d}$ & $1.25 \pm 0.24 \mathrm{~d}$ \\
Ubipro::PaFT & 5 & $0.03 \pm 0.05 \mathrm{a}$ & $0.13 \pm 0.05 \mathrm{a}$ & $0.43 \pm 0.30 \mathrm{a}$ \\
\hline
\end{tabular}

\begin{tabular}{lclll}
\hline Treatment & $\begin{array}{l}\text { Number of plants } \\
\text { examined }\end{array}$ & Number of Leaf & \\
\cline { 2 - 5 } & & 12 weeks & 16 weeks & 20 weeks \\
\hline WT & 16 & $1.00 \pm 0.00 \mathrm{a}$ & $1.50 \pm 0.57 \mathrm{a}$ & $2.50 \pm 0.57 \mathrm{a}$ \\
BA 1 ppm GA3 5 ppm & 19 & $1.50 \pm 0.57 \mathrm{~b}$ & $2.25 \pm 0.50 \mathrm{~b}$ & $3.25 \pm 0.50 \mathrm{~b}$ \\
BA 3 ppm GA3 10 ppm & 19 & $1.75 \pm 0.50 \mathrm{~b}$ & $2.50 \pm 0.57 \mathrm{~b}$ & $3.75 \pm 0.95 \mathrm{~b}$ \\
BA 9 ppm GA3 15 ppm & 20 & $2.25 \pm 0.50 \mathrm{c}$ & $3.00 \pm 0.00 \mathrm{c}$ & $4.75 \pm 0.95 \mathrm{c}$ \\
Ubipro::PaFT & 5 & $0.33 \pm 0.57 \mathrm{a}$ & $1.33 \pm 1.15 \mathrm{a}$ & $2.67 \pm 1.15 \mathrm{~b}$ \\
\hline
\end{tabular}

\begin{tabular}{lclll}
\hline Treatment & $\begin{array}{l}\text { Number of plants } \\
\text { examined }\end{array}$ & Root Length $(\mathrm{cm})$ & \\
\cline { 2 - 5 } & 16 & 12 weeks & 16 weeks & 20 weeks \\
\hline WT & 19 & $0.00 \pm 0$ & $0.51 \pm 0.08 \mathrm{a}$ & $1.80 \pm 0.38 \mathrm{a}$ \\
BA 1 ppm GA3 5 ppm & 19 & $0.00 \pm 0$ & $0.10 \pm 0.01 \mathrm{~b}$ & $1.55 \pm 0.31 \mathrm{~b}$ \\
BA 3 ppm GA3 10 ppm & 20 & $0.00 \pm 0$ & $0.04 \pm 0.01 \mathrm{c}$ & $1.02 \pm 0.17 \mathrm{c}$ \\
BA 9 ppm GA3 15 ppm & 5 & $0.00 \pm 0$ & $0.01 \pm 0.01 \mathrm{c}$ & $0.62 \pm 0.22 \mathrm{c}$ \\
Ubipro::PaFT & & & & $0.06 \pm 0.05 \mathrm{~d}$ \\
\hline
\end{tabular}

\begin{tabular}{lclll}
\hline Treatment & $\begin{array}{c}\text { Number of plants } \\
\text { examined }\end{array}$ & Number of Root & \\
\cline { 2 - 5 } & & 12 weeks & 16 weeks & 20 weeks \\
\hline WT & 16 & $0.00 \pm 0$ & $1.67 \pm 0.57 \mathrm{a}$ & $4.50 \pm 0.70 \mathrm{a}$ \\
BA 1 ppm GA3 5 ppm & 19 & $0.00 \pm 0$ & $1.33 \pm 0.57 \mathrm{a}$ & $3.50 \pm 0.57 \mathrm{a}$ \\
BA 3 ppm GA3 10 ppm & 19 & $0.00 \pm 0$ & $1.00 \pm 0 \mathrm{~b}$ & $3.00 \pm 0 \mathrm{ab}$ \\
BA 9 ppm GA3 15 ppm & 20 & $0.00 \pm 0$ & $0.50 \pm 1.00 \mathrm{~b}$ & $2.50 \pm 0.70 \mathrm{~b}$ \\
Ubipro::PaFT & 5 & $0.00 \pm 0$ & $0.00 \pm 0$ & $0.06 \pm 0.57 \mathrm{c}$ \\
\hline
\end{tabular}

At 12 weeks old after treated with $B A+G A 3$ the growth rate become faster than that of wild type plants, especially on the leaf length and leaf number, but not in transgenic plants. Table 1 shows that the highest leaf length and leaf number were reached after treated with a combination of 9 ppm BA + 15 ppm GA3. Onthe other hand, the lowest degree was the Ubipro::PaFT transgenic plant. The size and shape of leaves of transgenic plants are no difference compare with the wild type (non transformant) plants. Flower initiation does not occurred yet. Therefore the analysis of juvenile gene $\mathrm{POH} 1$ (for shoot initiation) and flower initiation gene $P a F T$ is become very important to understand the molecular regulation inside the plants after flowering induction. 


\section{Accumulation of the $\mathrm{POH} 1$ and PaFT transcripts in P. amabilis after flowering induction}

Table 2 shows that transformation of Ubipro::PaFT was about $2.2 \%$ and of only vector about $2.9 \%$. This efficiency is higher than our previos work using KNAT1 gene in P. amabilis (Semiarti et al. 2007) and it is good enough to get transgenic plants

RT-PCR analyses of POH1 and PaFT genes in P. amabilis after flowering induction show that in wild type/normal plants $\mathrm{POH} 1$ gene transcript can be detected in early development from four weeks old and 8 weeks, it decreased at 16 weeks and disappeared at 6 months. Oppositely, the transcript of flower initiation gene PaFT in wiltype can not be detected at juvenile stages, it appeared at 6- and 24- months old plants. At plants that treated by both phytohormones and Ubipro::PaFT gene insertion show both the transcript of $\mathrm{POH1}$ and $P a F T$. It indicates that genetic regulation between juvenile and reproductive genes in plants altered by both physiological and genetic treatments. As reported by Hew and Yong (1997), that flowering regulation in $P$. amabilis needs an extreem environmental condition such as cold shock for several days prior to flower initiation, high humidity, photoperiod, prominent temperature different of day and night. In Dendrobium, in vitro flowering can be occurred less than one year using BA as physiological treatment (Hee et. Al., 2009; Sim et al., 2007). Taken together these data indicated that induction of in vitro flowering in P. amabilis in this work affect the time of Flowering initiation gene expression but not enough to initiate flower bud initiation. Some environmental condition should be set up to get flower formation.

Table 2. Transformation efficiency and transgene analysis

\begin{tabular}{|c|c|c|c|c|c|c|}
\hline \multirow[t]{2}{*}{ Genotype } & \multirow{2}{*}{$\begin{array}{l}\text { Number of } \\
\text { Protocorms } \\
\text { examined }\end{array}$} & \multirow{2}{*}{$\begin{array}{l}\text { Survival protocorm } \\
\text { on Hygromycin } \\
\text { containing selection } \\
\text { medium }\left(\mathrm{Hyg}^{\mathrm{r}}\right) \\
\end{array}$} & \multicolumn{2}{|c|}{ DNA analysis } & \multicolumn{2}{|c|}{ RT-PCR } \\
\hline & & & HPT & $P a F T$ & $\mathrm{POH} 1$ & $\mathrm{PaFT}$ \\
\hline $\begin{array}{l}\text { WT (Non } \\
\text { Transformant) }\end{array}$ & 1325 & 0 & $3 / 0$ & $3 / 0$ & $2 / 2$ & $2 / 2$ \\
\hline Vector only & 1273 & $37(2.9 \%)$ & $3 / 3$ & $3 / 0$ & $2 / 2$ & $2 / 2$ \\
\hline Ubipro:: PaFT & 1469 & $33(2.2 \%)$ & $3 / 3$ & $3 / 3$ & $2 / 2$ & $2 / 2$ \\
\hline
\end{tabular}

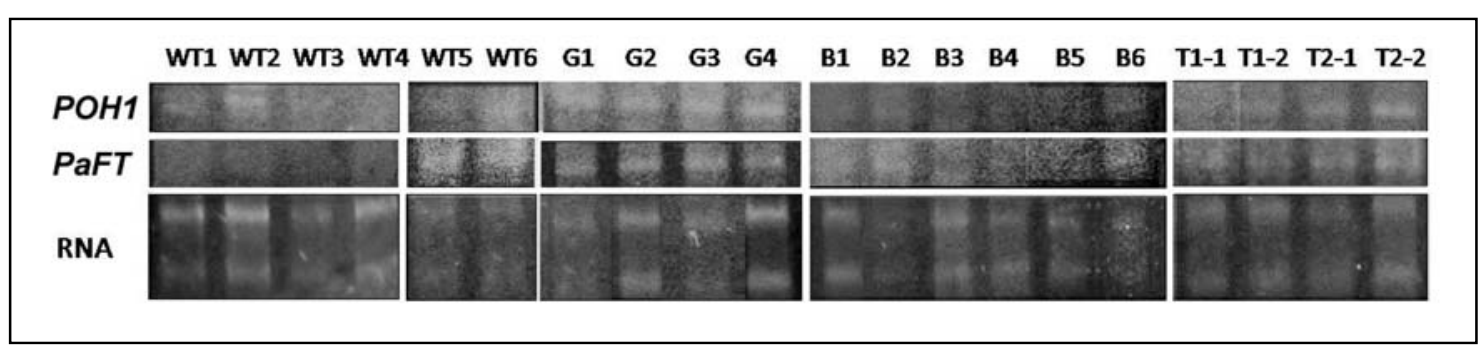

Figure 2. RT-PCR Analysis of transcripts of the POH1 and PaFT genes in wild type and transgenic $P$. amabilis orchids at several developmental stages.WT: wild type; WT1: 4 weeks old, WT2: 8 weeks old; WT3: 16 old; WT4: 6 months old; WT5: 12 months old; WT6: 24 months old; G series are $\mathrm{BA}+\mathrm{GA} 3$ treated plants, 6 months old. G1: wild type/Control, G2: 1 ppm BA + 5 ppm GA3; G3: 3 ppm BA+ 10 ppm GA3; 9 ppm BA + 15 ppm GA3. B1-B6: BA treated plants; B1: wild type/ control; B1: 1 ppm BA; B2: 3 ppm BA; B4: 5 ppm B5: 7 ppm BA, B6: 9 ppm BA. T series: Transgenic plants; T1-1 and T1-2: transformed by empty vector; T2-1 and T2-1 transgenic Ubipro::PaFT. T1-1 and T2-1: 12 months old, T1-2 andT2-2 24 months old.Data indicates that $P O H 1$ transcripts (800 bp) were detected at early stages in wiltype, but PaFT (530 bp) can be detected in P. amabilis after 12 months old. Induction of flowering by phytohormones BA and GA3 in combination increase the transcript of PaFT at 6 months old plant of WT. Transcripts of PaFT (730 bp) are detected in 12 and 24 months old transgenic plants. 


\section{CONCLUSION}

Initiation of flowering gene expression in $P$. amabilis orchids can be induced earlier by a combination of phytohormones 9 ppm BA and 15 ppm GA3 and the insertion of Ubipro::PaFT into orchid genome. The PaFT transgene might induced transcription of endogenous $P a F T$ in $P$. amabilis orchids.

\section{REFERENCES}

Hew, C.S., and J.W.H. Yong. 1997. The Physiology of Tropical Orchids in Relation to The Industry. World Scientific Publ. $370 \mathrm{p}$.

Hee, K.H., H.H. Yeoh, and C.S. Loh. 2009. In vitro flowering and in vitro pollination: methods that will ...

Howell, S.H. 1998. Molecular Genetics of Plant Development. Cambridge University Press. UK.

Semiarti, E., A. Indrianto, A. Purwantoro, S. Isminingsih, N. Suseno, T. Ishikawa, Y. Yoshioka, Y. Machida, and C. Machida. 2007. Agrobacterium Mediated Transformation Of The Wild Orchid Species Phalaenopsis amabilis. Plant Biotechnology 24: 265-272.

Sim, G.E., C.S. Loh, and C.J. Goh. 2007. High frequency early in vitro flowering of Dendrobium Madame Thong-In (Orchidaceae). Plant Cell Rep 26: 383-393. 